$E_{s i t a s t a t}^{s}$ geht nicht darum, dass die Steuersätze in den Oasen niedriger sind als in der „Wüste" ringsherum. Hochsteuerländer wissen, dass sie den Steuerwettbewerb aushalten müssen. Schließlich bieten sie bessere Produktionsbedingungen für investitionsbereite Unternehmen und größere Sicherheiten für anlagebereites Kapital. Ohnehin sind Steueroasen in den seltensten Fällen auch Produktionsstandorte. Was die Hochsteuerländer ärgert, ist etwas anderes. Wesentliche Teile der auf inren Territorien erwirtschafteten Kapitalerträge können dank der Steueroasen ihrem steuerlichen Zugriff entkommen. Dies liegt zunächst einmal an einer Eigenart des internationalen Steuerrechts: Während Gewinne generell nach dem "Quellenlandprinzip“ dort besteuert werden, wo sie anfallen, liegt das Besteuerungsrecht bei anderen Kapitalerträgen, vor allem Zinsen, in den Ländern, in denen die Empfänger der Erträge wohnen (,Wohnsitzlandprinzip“). Das macht es für Besitzer großer Finanzvermögen attraktiv, ihren Wohnsitz in Steueroasen zu nehmen. Doch auch dies müssen die Hochsteuerländer ertragen. Freizügigkeit ist ein hohes Gut. Zudem sind auch Vermögensbesitzer trotz einiger spektakulärer Ausnahmen eher bodenständig.

Kriminell wird die Angelegenheit, wenn sich Vermögensbesitzer die Vorteile der Niedrigbesteuerung verschaffen, ohne tatsächlich aus einem Hochsteuerland, z.B. Deutschland, in eine Oase zu ziehen. Wenig aussichtsreich ist allerdings eine nur behauptete Wohnsitzverlagerung; zumeist würde der Schwindel vom Finanzamt entdeckt. Erfolgreich war dagegen - zumindest bisher - ein anderes Schema: Steuerinländer übertragen ihr Vermögen an eine ausländische Kapitalsammelstelle, die ihrerseits die Zinserträge einnimmt. Die in der Oase domizilierte Bank (Fondsverwaltung, Stiftung oder was auch immer) ist

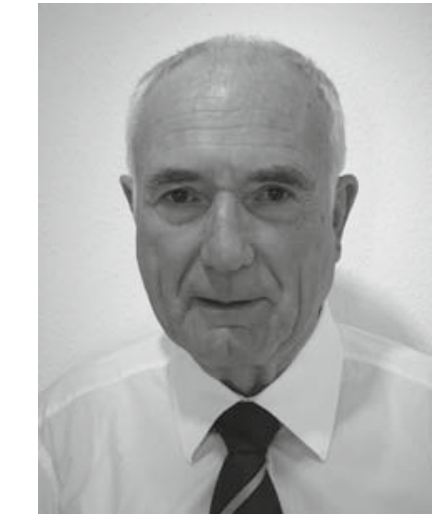

Gerold Krause-Junk

\section{Ende der Steueroasen in Sicht}

dann der primäre Empfänger der aus den Hochsteuerländern steuerfrei abfließenden Kapitalerträge, der sie anschließend dem eigentlichen Vermögensbesitzer gutschreibt. Da die Erträge das Rechenwerk der Bank gewissermaßen nur durchlaufen, spielt der Steuersatz der Oase die geringste Rolle. Auch dieses Schema muss nicht zwangsläufig zu einem Steuerbetrug führen; denn der Vermögensbesitzer oder die Kapitalsammelstelle könnten ja die Gutschrift dem zuständigen Finanzamt zur Kenntnis bringen. Warum dann aber der ganze Aufwand? Die Steuerhinterziehung gereicht allen Beteiligten zum Vorteil; die meisten Steueroasen leben davon.

Manche meinen, diese Art Steuerflucht sei die legitime Wehr des geschröpften Bürgers. Andere sehen in derartigen Hinterziehungsmodellen sogar ein notwendiges Ventil, das die Hochsteuerländer nutzen, um gewissermaßen den Steuerüberdruck aus dem Kessel zu lassen. Der Finanzwissenschaftler kann dem einen wie dem anderen Argument nichts Positives abgewinnen: Steuerhinterziehung der einen bedeutet höhere Steuern für die anderen. Das ist weder verteilungspolitisch noch unter Effizienzaspekten hinnehmbar. Aus diesem Dilemma der Hochsteuer- und
Produktionsländer gibt es grundsätzlich verschiedene Auswege. Zum einen könnten sie versuchen, die bisher steuerfrei hinausfließenden Kapitalerträge zu besteuern. Die neu eingeführte Zinsschranke ist ein derartiger Versuch, der allerdings erhebliche Probleme aufwirft. Ein anderer Weg richtet sich darauf, die vom Vermögensbesitzer freiwillig nicht vorgenommene Deklaration zu erzwingen. Wie jüngste Erfolgsmeldungen zeigen, ist die Finanzverwaltung dank rigoroser Bankbetriebsprüfungen durchaus nicht mehr hilflos. Einfacher wäre es aber allemal, wenn die ausländischen Sammelstellen ihrerseits Kontrollmitteilungen verschicken würden.

Das hätte man noch bis vor kurzem als guten Witz verkaufen können. Aber die Amerikaner haben vorgemacht, dass man auch Banken in Kapitalfluchtländern zur Kooperation zwingen kann. Denn die Banken sind letztlich darauf angewiesen, das innen übertragene Vermögen rentierlich anzulegen. Und wo anders könnten sie dies tun, als in den Hochsteuerländern, die zugleich die stärksten Produktionsregionen darstellen? Ohne Kooperation keine Zulassung! Im Übrigen spielt die Finanzkrise den Staaten in die Hände: die Banken haben zur Zeit schlechte Karten. Europa scheint vom Erfolg der Amerikaner gelernt zu haben. Es geht sogar ohne Kavallerie. So haben in letzter Zeit die meisten der bisher als Oasen verdächtigten Staaten eine Kooperation mit den Steuerbehörden des betroffenen Auslands angekündigt. Dazu zählen auch diejenigen europäischen Staaten, denen ihr „Bankgeheimnis" bisher heilig war. Sie werden bis zum Vollzug von der OECD auf einer „grauen“ Liste geführt. Selbst die wenigen „schwarzen“ Schafe haben inzwischen klein beigegeben.

Gerold Krause-Junk ist Emeritus für Finanzwissenschaft des Instituts für Ausländisches und Internationales Steuerwesen der Universität Hamburg 